\title{
THE EVOLUTION OF THE KREBS CYCLE: A PROMISING THEME FOR MEANINGFUL BIOCHEMISTRY LEARNING IN BIOLOGY
}

\author{
Costa, C. ; Galembeck, E.
}

Departamento de Bioquímica e Biologia Tecidual, Instituto de Biologia, Universidade Estadual de Campinas, Campinas, Brazil.

INTRODUCTION: Evolution has been recognized as a key concept for biologists. In order to motivate biology undergraduates for contents of central energetic metabolism, we addressed the Krebs cycle structure and functions to an evolutionary view. To this end, we created a study guide which contextualizes the emergence of the cyclic pathway, in light of the prokaryotic influence since early Earth anaerobic condition to oxygen rise in atmosphere. OBJECTIVES: The main goal is to highlight the educational potential of the material whose subject is scarcely covered in biochemistry textbooks. MATERIALS AND METHODS: The study guide is composed by three interrelated sections, the problem (Section 1), designed to arouse curiosity, inform and motivate students; an introductory text (Section 2) about life evolution, including early micro-organisms and Krebs cycle emergence, and questions (Section 3) for debate. The activity consisted on a peer discussion session, with instructors tutoring. The questions were designed to foster exchange of ideas in an ever-increasing level of complexity, and cover subjects from early atmospheric conditions to organization of the metabolism along the subsequent geological ages. RESULTS AND DISCUSSION: We noticed that students were engaged and motivated by the task, especially during group discussion. Based on students' feedbacks and class observations, we learned that the material raised curiosity and stimulated discussion among peers. It brought a historical and purposeful way of dealing with difficult biochemical concepts. CONCLUSIONS: The whole experience suggests that the study guide was a stimulus for broadening comprehension of the Krebs cycle, reinforcing the evolutionary stance as an important theme for biology and biochemistry understanding. On the other hand, we do not underestimate the fact that approaching Krebs cycle from an evolutionary standpoint is a quite complex discussion for the majority of students. KEYWORDS: Evolution. Krebs cycle. Metabolism learning. Biology. ACKNOWLEDGEMENTS: We thank Capes for financial support. 